\title{
Polygodial, the Fungitoxic Component from the Brazilian Medicinal Plant Polygonum punctatum
}

\author{
Tânia Maria de Almeida Alves, Fabiane Lacerda Ribeiro, Helmut Kloos, \\ Carlos Leomar Zani ${ }^{+}$
}

Laboratório de Química de Produtos Naturais, Centro de Pesquisas René Rachou-Fiocruz, Av. Augusto de Lima 1715, 30190-002 Belo Horizonte, MG, Brasil

Polygonum punctatum (Polygonaceae) is an herb known in some regions of Brazil as "erva-debicho" and is used to treat intestinal disorders. The dichloromethane extract of the aerial parts of this plant showed strong activity in a bioautographic assay with the fungus Cladosporium sphaerospermum. The bioassay-guided chemical fractionation of this extract afforded the sesquiterpene dialdehyde polygodial as the active constituent. The presence of this compound with antibiotic, anti-inflammatory and anti-hyperalgesic properties in "erva-de-bicho" may account for the effects attributed by folk medicine to this plant species.

Key words: medicinal plants - Cladosporium sphaerospermum - antifungal - polygodial - sesquiterpene - Brazil

Several plant species of the genus Polygonum (Polygonaceae) are used in the folk medicine at different parts of the world to treat many diseases including skin infections, dysentery, snake-bite, hemorrhoids, insomnia and heart diseases and is also used for liver protection (WHO 1989a,b, 1998a,b). According to the NAPRALERT database, in Latin America and North America Polygonum punctatum Elliot is used in some areas to treat a diversity of ailments including hemorrhoids, diarrhoea, colds and influenza. In Brazil, $P$. punctatum (syn. Persicaria punctata and $P$. acre) is popularly known as "erva-de-bicho", "capiçoba", "pimenta-d'água", "pimenta-do-brejo" and "cataia" (Corrêa 1984). It is used to treat hemorrhoids and rheumatism, as an abortive, a diuretic and a hemenagogue (Martins et al. 1995). Previous pharmacological studies with the ethanol/water extract of the entire plant disclosed antihistaminic, anti-inflammatory, antipyretic and hypotensive activities (Oliveira-Simões et al. 1989). Toxicity assays of the methanolic and aqueous extracts in the rat model indicated an $\mathrm{LC}_{50}>$ $1 \mathrm{~g} / \mathrm{kg}$ (Bhakuni et al. 1969).

In our search for bioactive compounds from the Brazilian flora, we screened hundreds of plant extracts, including those from medicinal plants, for

Supported by CNPq/ Fiocruz/ Pronex.

${ }^{+}$Corresponding author. Fax: +55-31-3295.3566.

E-mail: zani@ cpqrr.fiocruz.br

Received 26 October 2000

Accepted 3 January 2001 fungitoxic activity against Cladosporium sphaerospermum (Alves et al. 2000) using a bioautographic assay based on the protocol described by Homans and Fuchs (1970). The crude dichloromethane extract of aerial parts of $P$. punctatum was one of the most active. Aiming to isolate and identify the fungitoxic compound(s) we investigated this extract using a bioassay-guided chemical fractionation protocol.

\section{MATERIALS AND METHODS}

Plant collection - The aerial parts of the plant were collected at Governador Valadares, State of Minas Gerais, Brazil. A voucher specimen was deposited in the Department of Botany Herbarium, Universidade Federal de Minas Gerais, under the code BHCB 41475.

Extraction - The plant was dried at $45^{\circ} \mathrm{C}$ in a convection oven and powdered in a knife mill. The powder $(85 \mathrm{~g})$ was macerated at room temperature for $24 \mathrm{~h}$ in dichloromethane. After filtration, the solvent was removed by rotary evaporation under reduced pressure and at temperatures below $45^{\circ} \mathrm{C}$ affording $2 \mathrm{~g}$ of crude extract.

Isolation and identification of pure compound - The crude extract $(500 \mathrm{mg}$ ) was submitted to centrifugal circular chromatography using hexane/ ethanol/water (10:9:1). Thirty fractions were collected. The fungitoxic fractions 11 to 13 were grouped (31 mg) and chromatographed on a silicagel column eluted with dichloromethane. A white solid ( $5 \mathrm{mg}, 0.23 \%$ yield from dry plant) was obtained as the active compound.

Bioautographic assay with C. sphaero spermum- The procedure of Homans and Fuchs (1970) was adapted. Briefly, the extract, fractions 
and pure compound $(100 \mu \mathrm{g})$ were spotted on TLC plates using the appropriate volatile solvents (10 $\mu \mathrm{l})$. After complete solvent removal, a spore suspension of the fungus in nutrient medium was sprayed and the TLC plates incubated in a moist atmosphere for three days at room temperature. Crude extract and fractions were eluted on TLC using appropriate solvents and the bioautographic procedure described above was used to locate the active component in the mixture. The appearance of a growth inhibition zone around the spot indicated the fungitoxic activity. Thymol $(50 \mu \mathrm{g} / \mathrm{spot})$ and solvents $(10 \mu \mathrm{l})$ were used as controls.

Physical data of polygodial $[\alpha]_{\mathrm{D}}^{25}=-27^{\circ}$ $\left(\mathrm{CH}_{2} \mathrm{Cl}_{2}, c=0.1\right) .{ }^{13} \mathrm{C}$ NMR (Brucker, $100 \mathrm{MHz}$, $\left.\mathrm{CDCl}_{3}\right): 39.61(\mathrm{t}, \mathrm{C} 1) ; 18.05(\mathrm{t}, \mathrm{C} 2) ; 41.82(\mathrm{t}, \mathrm{C} 3)$; 29.71 (s, C4); 49.03 (d, C5); 25.24 (t, C6); 153.96 (d, C7); 138.48 (s, C8); 60.36 (d, C9); 36.93 (s, C10); 201.89 (d, C11); 193.21 (d, C12); 21.96 (q, C13); 33.14 (q, C14); 15.29 (q, C15). ${ }^{1} \mathrm{H}$ NMR (Brucker, $400 \mathrm{MHz}, \mathrm{CDCl}_{3}$ ): 9.54 (d, J=4.4, $\mathrm{H11}$ ); 9.46 (s, H12); 7.13 (m, H7); 2.83 (m, H9); 2.51 (m, H6); 2.32 (m, H6); 1.85 (m, H1); $0.96\left(\mathrm{~s}, \mathrm{CH}_{3}\right)$; $0.95\left(\mathrm{~s}, \mathrm{CH}_{3}\right) ; 0.92\left(\mathrm{~s}, \mathrm{CH}_{3}\right)$.

\section{RESULTS AND DISCUSSION}

$P$. punctatum was collected in 1998 during an ethnomedical survey in the vicinity of Governador Valadares. This plant was reported by local people to be an effective treatment for intestinal disorders. The dichloromethane extract of its aerial parts showed a strong antifungal activity in our screening procedure using the bioautographic assay with spores of $C$. sphaerospermum. This result is in agreement with the findings published by Zacchino et al. (1998) showing that the dichloromethane extracts of the aerial parts of $P$. punctatum was active against a panel of yeasts, filamentous fungi and dermatophytes. Interestingly, Rahalison et al. (1993) reported that the extract from the roots of $P$. punctatum collected in Panama was inactive when tested in a similar assay using Cladosporium curcumerium and Candida albicans. The lack of information concerning the component responsible for the antifungal activity prompted us to pursue the isolation and identification of the active compound using a bioassay-guided protocol.

Centrifugal planar chromatography of the crude extract afforded fractions enriched with the active compound. They were grouped and subjected to column chromatography over silica gel to yield a crystalline compound $(5 \mathrm{mg}$ ) with strong antifungal activity against $C$. sphaerospermum. Analysis of the NMR spectral data of this compound and comparison with published values (Fukuyama et al. 1985) allowed us to identify it as polygodial (Figure). To the best of our knowledge, this is the

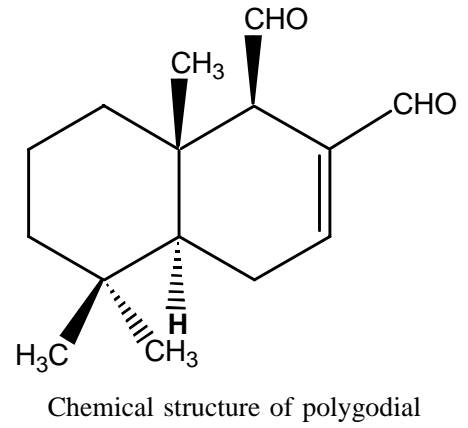

first report describing the presence of polygodial in P. punctatum.

Polygodial, a drimane type dialdehyde sesquiterpene, was first isolated in 1962 from $P$. hydropiper L. (Barnes \& Loder 1962). This compound presents, among other properties, insect antifeedant, antibiotic and antifungal activities. The first report of its activity against $C$. albicans was provided by McCallion et al. in 1982. More recently, Lee et al. (1999) demonstrated that besides C. albicans polygodial is as active in vitro as amphotericin B against other yeast like fungal pathogens. Previous chemical work with $P$. punctatum showed the presence of a hemiacetal derivative of polygodial that was inactive against a tick (Boophilus microplus) (Echeverri et al. 1997). Hagendoorn et al. (1994) demonstrated that in $P$. hydropiper, polygodial is present only in the aerial parts of the plant. This fact, together with our findings and those of Zacchino et al. (1998) and Rahalison et al. (1993), allow us to hypothesize that in P. punctatum too, polygodial is restricted to the aerial parts of the plant.

Concluding, the presence of a strong antibiotic compound such as polygodial, that also displays anti-hyperalgesic properties in models of inflammatory and neurogenic pain (Mendes et al. 1998), supports the ethnomedical use of this plant for the treatment of intestinal pains and infections.

\section{ACKNOWLEDGMENTS}

To Dr Julio Lombardi and Dr Lucia Pimenta of the Federal University of Minas Gerais, Brazil, for the plant identification and for optical rotation measurement, respectively. To the University of Illinois at Chicago for the permission to access the NAPRALERT database.

\section{REFERENCES}

Alves TMA, Silva AF, Brandão M, Grandi TSM, Smânia EFA, Smânia Jr A, Zani CL 2000. Biological screening of Brazilian medicinal plants. Mem Inst Oswaldo Cruz 95: 367-373.

Barnes CS, Loder JW 1962. Structure of Polygodial - a new sesquiterpene dialdehyde from Polygonum hydropiper L. Australian J Chem 15: 322. 
Bhakuni OS, Dhar ML, Dhar MM, Dhawan BN, Mehrotra BN 1969. Screening of Indian plants for biological activity. Part II. Indian J Exp Biol 7: 250262.

Corrêa MP 1984. Dicionário das Plantas Úteis do Brasil $e$ das Exóticas Cultivadas, Vols I-VI, IBDF, Ministério da Agricultura, Rio de Janeiro.

Echeverri F, Luis JG, Torres F, Quinones W, Alzate F, Cardona G, Archbold R, Roldan J, Lahlou EH 1997. Danilol, a new drimane sesquiterpene from Polygonum punctatum leaves. Nat Prod Lett 10: 295301.

Fukuyama Y, Sato T, Miura I, Asakawa Y 1985. Drimane-type sesqui- and norsesquiterpenoids from Polygonum hydropiper. Phytochemistry 24: 15211524.

Hagendoorn MJM, Geelen TAM, Vanbeek TA, Jamar DCL, Tetteroo FAA, Vanderplas LHW 1994. Occurrence of polygodial in plant organs and tissueculture of Polygonum hydropiper. Physiologia Plantarum 92: 595-600.

Homans AL, Fuchs A 1970. Direct bioautography on thin layer chromatograms as a method for detecting fungitoxic substances. J. Chromatogr 51: 327-329.

Lee SH, Lee JR, Lunde CS, Kubo I 1999. In vitro antifungal susceptibilities of Candida albicans and other fungal pathogens to polygodial, a sesquiterpene dialdehyde. Planta Med 65: 204-208.

Martins ER, Castro DM, Castellani DC, Dias JE 1995. Plantas Medicinais, Imprensa Universitária, UFV, Viçosa, p. 117-118.

McCallion RF, Cole ALJ, Walker JRL, Blunt JW, Munro MHG 1982. Antibiotic substances from NewZealand plants., 2. Polygodial, an anti-candida agent from Pseudowintera colorata. Planta Med 44: 134138.

Mendes GL, Santos ARS, Campos NM, Tratsk KS, Yunes RA, Filho VC, Calixto JB 1998. Anti-hyperalgesic properties of the extract and of the main sesquiterpene polygodial isolated from the barks of Drymis winteri (Winteraceae). Life Sciences 63: 369381.

Oliveira-Simões CM, Ribeiro-do-Vale RM, Poli A, Nicolau M, Zanin M 1989. Pharmacological investigation on Polygonum punctatum Elliott (=P. acre H.B.K.) extracts. Part I. Tests in vivo. J Pharm Belg 44: 275-284.

Rahalison L, Hamburger M, Hostettmann K, Monod M, Frenk E, Gupta MP, Santana AI, Correa MD, Gonzalez AG 1993. Int J Pharmacog 31: 68-76.

WHO-World Health Organization 1989a. Medicinal Plants in China, Western Pacific Series no. 2, p. 227 229.

WHO-World Health Organization 1989b. Medicinal Plants in Viet Nam, Western Pacific Series no. 3, p. 307-309.

WHO-World Health Organization 1998a. Medicinal Plants in the South Pacific, Western Pacific Series no. 19 , p. 153.

WHO-World Health Organization 1998b. Medicinal Plants in the Republic of Korea, Western Pacific Series no. 21, p. 217-219.

Zacchino S, Santecchia C, Lopez S, Gattuso S, Munoz JD, Cruanes A, Vivot E, Cruanes MD, Salinas A, de Ruiz RE, Ruiz S 1998. In vitro antifungal evaluation and studies on mode of action of eight selected species from the Argentine flora. Phytomedicine 5: 389-395. 
834 Fungitoxic Component from P. punctatum • Tânia Maria de Almeida Alves et al. 